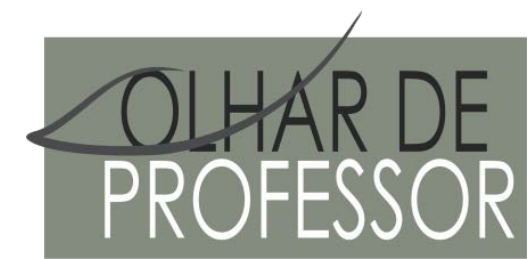

DOI: 10.5212/OLHARPROFR.v2111.0004

\title{
FORMAÇÃO INICIAL E CONTINUADA DE PROFESSORES INDÍGENAS: TESES E DISSERTAÇ̃̃ES 2010-2017
} INITIAL AND CONTINUED INDIGENOUS TEACHERS' EDUCATION: BRAZILIAN DISSERTATIONS 2010-2017 FORMACIÓN INICIAL Y CONTINUADA DE PROFESORES INDÍGENAS: TESIS Y DISERTACIONES २०10-2017

\author{
ARLINDO LINS DE MELO JUNIOR* \\ IVAN FORTUNATO*
}

\begin{abstract}
Resumo: O tema “formação de professores indígenas” remete a uma importante reflexão sobre as tarefas da educação. Neste estudo, objetivamos analisar a formação inicial e continuada do professor indígena brasileiro nas produções acadêmicas (teses e dissertações). Desenvolveu-se uma revisão sistemática, a partir de um levantamento da produção do conhecimento (dissertações e teses) na base de dados da Biblioteca Digital Brasileira de Teses e Dissertações (BDTD). Os resultados revelam significativo aumento na formação inicial e continuada do professor indígena preocupada com o contexto em que vivem os povos indígenas e consequentemente a uma valorização da cultura e biliguismo.
\end{abstract}

Palavras-chave: Formação de professores indígenas; Educação; Cultura.

\begin{abstract}
The issue of “indigenous teachers' education" leads to an important reflection on the tasks of education. In this study, we aimed to analyze the initial and continued formation of the Brazilian indigenous teachers in academic productions (doctoral and masters dissertations). A systematic review was developed, based on a survey of knowledge production from the database of the Brazilian Digital Library of Theses and Dissertations (BDTD). The results show a significant increase in the initial and continued indigenous teacher's education concerned with the context in which the indigenous people live and, consequently, a valorization of culture and bilingualism.
\end{abstract}

Keywords: Indigenous teacher education; Education; Culture.

Resumen: El tema "formación de profesores indígenas" remite a una importante reflexión sobre las tareas de la educación. En este estudio, objetivamos analizar la formación inicial y continuada del profesor indígena brasileño en las producciones académicas (tesis y disertaciones). Se desarrolló una revisión sistemática, a partir de un levantamiento de la producción del conocimiento (disertaciones y tesis) en la base de datos de la Biblioteca Digital Brasileña de Tesis y Disertaciones (BDTD). Los resultados revelan un significativo aumento en la formación inicial y continuada del profesor indígena preocupada por el contexto en que viven los pueblos indígenas y consecuentemente a una valorización de la cultura y el biliguismo.

Palabras clave: Formación de profesores indígenas; la educación; Cultura.

\footnotetext{
* Mestre em Educação pelo PPGEd/UFSCar Sorocaba. E-mail: arlindolins@yahoo.com.br

*** Doutor em Desenvolvimento Humano e Tecnologias e doutor em Geografia pela UNESP. Coordenador da licenciatura em Formação Pedagógica/IFSP e professor permanente do PPGEd/UFSCar Sorocaba. E-mail: ivanfrt@yahoo.com.br
} 


\section{INTRODUÇÃO}

É como se as vozes das sociedades indígenas, há séculos silenciadas pelas políticas educacionais, finalmente pudessem formular e explicitar seu projeto de escola, fazêlo ecoar e reproduzir, ainda que sob intenso debate e conflito, em forma de novas propostas de políticas públicas a serem desenvolvidas pelo Estado brasileiro. (MONTE, 2000, p. 8).

Pensar na formação de professores remete a uma reflexão sobre as tarefas da educação, inclusive sobre o viés da educação escolar indígena. Esta, conforme lemos na epígrafe, silenciada por séculos nas políticaseducacionais no nosso país, mascomeça a ganhar contornos um pouco mais nítidos no limiar do século passado. Contudo, como tem sido trabalhada a formação inicial e a formação continuada de professores que atuam no campo da educação escolar indígena no Brasil? Para tentar esboçar algumas respostas para essa pergunta-problema, o presente estudo consiste em uma revisão sistemática de teses e dissertações nacionais a respeito da formação de professores indígenas e para a educação indígena.

Silva (2000) escreveu a respeito do Movimento dos Professores Indígenas da região amazônica. Este era um, dentre vários, movimentos desenvolvidos que despontavam na década de 1980, na qual se batalhava por "escolas verdadeiramente indígenas [...] que contribuam para o processo histórico de sobrevivência como povos.” (p. 36). Como reflexo desses, e outros, movimentos sociais, vimos despontar vários dispositivos legais que garantem aos povos indígenas a escolarização e adentramento no sistema regular de ensino (BRASIL, 2015; 2010; 1996; 1988). A Constituição Federal de 1988, por exemplo, remete ao direito da população indígena brasileira a sua identidade étnica como povo com Línguas diferenciadas e cultura diversificada. Ainda, a Lei de Diretrizes e Bases da Educação Nacional, nos artigos 78 e 79, reafirma ser dever do Estado a oferta de uma educação escolar bilíngue e intercultural, assim como o acesso ao conhecimento indígena e não indígena.

Ainda, a educação escolar indígena é tratada com propriedade no Decreto $\mathrm{n}^{\circ} 6.861$ de 27 de maio de 2009, o qual dispõe sobre a Educação Escolar Indígena e define sua organização em territórios etnoeducacionais ${ }^{1}$, dando providências de atenção às populações indígenas, apresentando proposta para sua organização e funcionamento da educação escolar para os povos indígenas. Segundo o mesmo decreto, tais providências deverão ser feitas a partir dos territórios etnoeducacionais, levando em conta as necessidades e particularidades de cada um.

Qual teria sido o impacto dessas propostas e diretrizes na formação docente? Neste artigo, o objetivo principal é identificar reflexos dessa legislação educacional no pensamento acadêmico, especificamente, buscando verificar como a formação inicial e continuada do professor indígena brasileiro tem sido analisada e discutida nas produções acadêmicas nacionais. Assim sendo, trata-se de um estudo de revisão sistemática, a partir de um levantamento da produção do conhecimento (dissertações e teses) na base de dados da Biblioteca Digital Brasileira de Teses e Dissertações (BDTD). Mas, como os reflexos nunca são imediatos na educação, optou-se pelo levantamento da produção mais recente, considerando os últimos anos, retroagindo de 2016 até o início desta década. Portanto, o recorte temporal analisado é o período 2010-2016.

Para alcançar o objetivo proposto, o artigo apresenta-se em três seções, sendo a primeira a descrição da metodologia e da apresentação dos dados encontrados. Na sequência discutimos, a partir das teses e dissertações inventariadas, a formação inicial de professores indígenas e, por último, a formação continuada. Ao final, esperamos que esta revisão ajude a compreender melhor o estado atual

\footnotetext{
${ }^{1}$ Cada Território Etnoeducacional compreenderá, independentemente da divisão político-administrativa do País, as terras indígenas, mesmo que descontínuas, ocupadas por povos indígenas que mantêm relações intersocietárias caracterizadas por raízes sociais e históricas, relações políticas e econômicas, filiações lingüísticas, valores e práticas culturais compartilhados. (BRASIL, 2009).
} 
das pesquisas nacionais sobre a educação escolar indígena, e que nossos achados possibilitem o avanço de novas e mais densas pesquisas. Espera-se, ainda, que colabore com a proposta de novas políticas públicas e políticas educacionais.

\section{DA REVISÃO SISTEMÁTICA E SEUS RESULTADOS}

Ao acessar a Biblioteca Digital Brasileira de Teses e Dissertações (BDTD), realizamos buscas a partir das seguintes palavras-chaves: "formação de professores"; "formação de professores indígenas"; “formação inicial”; “formação continuada”; "povos indígenas”; “índios”; “aldeias” e "educação”. Tratam-se de termos copilados mais representativos da literatura científica educacional, disponibilizados na pesquisa "thesaurus" da Educação Brasileiro da Educação (BRASED), vinculada ao Instituto Nacional de Estudos e Pesquisas Educacionais Anísio Teixeira (INEP). Reitera-se que foram realizadas combinações das palavras-chave, pontuadas com o auxílio do indicador booleano AND. Assim, essas palavras foram permutadas em expressões de dois a três termos para a busca na base de dados citada, da seguinte maneira: "Formação de professores AND povos indígenas", "formação de professores AND índios”, "formação de professores indígenas AND educação", "formação de professores AND aldeias", "formação inicial AND povos indígenas e "formação continuada AND povos indígenas”.

O processo de busca e seleção das pesquisas ocorreu durante os meses de agosto a outubro de 2017, considerando, portanto, apenas teses e dissertações defendidas até o ano de 2016. Assim, os critérios para primeira análise das pesquisas incluídas e os de recorte específico foram constituídos na leitura exaustiva dos títulos e resumos disponíveis na BDTD, seguindo roteiro de análise adaptado de levantamento sistemático anterior. (PEREIRA; FORTUNATO; LOURENÇO, 2016). Tal roteiro adaptado visa catalogar as informações técnicas, tais como ano de defesa, instituição, modalidade e o programa de pós-graduação na qual foi defendida a pesquisa, além de informações qualitativas, como aspectos metodológicos e os objetivos. A especificidade desta revisão, ainda, levou à inclusão da etnia indígena pesquisada como categoria de análise.

Além do roteiro, foram estabelecidos os seguintes critérios de elegibilidade, para inclusão da dissertação ou tese no rol de produtos a serem analisados: (1) o produto deveria ser uma tese ou dissertação em língua portuguesa ${ }^{2}$, (2) o produto deveria tratar da formação de professores indígenas especificamente no contexto brasileiro, e (3) o produto deveria, via repositório institucional, por exemplo, disponibilizar de forma livre e gratuita seu conteúdo na íntegra.

Depois das buscas das palavras-chaves combinadas e do uso dos três critérios de elegibilidade, localizou-se 43 produtos. Deste total, contudo, 11 apareceram em duplicidade ao se utilizar diferentes palavras-chaves, totalizando, portanto, 34 produtos distintos. Na sequência, nova filtragem foi feita, levando à exclusão de 13 dissertações ou teses que não tratavam da formação de professores com um olhar pautado na perspectiva da educação escolar indígena ou apenas citava o tema formação de professores indígenas esporadicamente. Dessa forma, o levantamento sistemático resultou em 21 produtos considerados pertinentes para análise.

Os primeiros passos, conforme roteiro proposto, trata-se da análise técnica, a qual visa identificar o ano de defesa, a modalidade (dissertação ou tese), e a área do programa. Seus autores foram identificados pelo sobrenome e os itens da análise técnica mapeados foram dispostos no Quadro 01, a seguir, em ordem cronológica:

\footnotetext{
${ }^{2}$ Na BDTD são disponibilizados produtos gerados fora do Brasil, em programas de pós-graduação, mas que foram validados como mestrado ou doutorado. Nesse sentido, torna-se elegível nesta revisão produtos estrangeiros, desde que disponíveis em língua portuguesa.
} 
Quadro 01. Resultado da análise técnica.

\begin{tabular}{|c|c|c|c|c|c|}
\hline Defesa & Autoria & Modalidade & Instituição & Programa & $\begin{array}{c}\text { Área de } \\
\text { concentração }\end{array}$ \\
\hline \multirow{2}{*}{2010} & Burrato & \multirow{4}{*}{ Tese } & UFSCAR & Educação Especial & \multirow{3}{*}{ Educação } \\
\hline & Leme & & \multirow{2}{*}{ USP } & \multirow{2}{*}{ Educação } & \\
\hline \multirow{4}{*}{2011} & Bendazzoli & & & & \\
\hline & Bernardi & & UFSC & $\begin{array}{c}\text { Educação Científica e } \\
\text { Tecnológica }\end{array}$ & Ensino \\
\hline & Orellana & Dissertação & PUC-SP & \multirow{7}{*}{ Educação } & \multirow{7}{*}{ Educação } \\
\hline & Soares & Tese & \multirow{2}{*}{ UFMG } & & \\
\hline \multirow{3}{*}{2012} & Brito & \multirow{3}{*}{ Dissertação } & & & \\
\hline & Antunes & & UFRGS & & \\
\hline & Silva & & UFM & & \\
\hline \multirow{5}{*}{2013} & Ferreira & Tese & UFRGS & & \\
\hline & Maders & \multirow{4}{*}{ Dissertação } & UFSM & & \\
\hline & $\begin{array}{l}\text { Nascimento } \\
\text { Filho }\end{array}$ & & EST & Teologia & Teologia \\
\hline & Ribeiro & & UFC & $\begin{array}{c}\text { Políticas Públicas e Gestão } \\
\text { da Educação Superior }\end{array}$ & Interdisciplinar \\
\hline & Sousa & & UFJF & $\begin{array}{l}\text { Gestão e Avaliação em } \\
\text { Educação Pública }\end{array}$ & Educação \\
\hline 2014 & Marcelino & \multirow{2}{*}{ Tese } & UFES & \multirow{2}{*}{ Educação } & \multirow{2}{*}{ Educação } \\
\hline \multirow{4}{*}{2015} & Alves & & PUC-GO & & \\
\hline & Dias & \multirow[b]{2}{*}{ Dissertação } & UNIVATES & Ensino & \multirow[b]{2}{*}{ Ensino } \\
\hline & Santos & & PUC-RS & $\begin{array}{c}\text { Educação em Ciências e } \\
\text { Matemática }\end{array}$ & \\
\hline & Silva & Tese & UFPR & Educação & Educação \\
\hline \multirow[t]{2}{*}{2016} & Gonçalves & Dissertação & UNILA & $\begin{array}{c}\text { Interdisciplinalidade em } \\
\text { Estudos Latino-Americanos }\end{array}$ & Interdisciplinar \\
\hline & Valentini & Tese & PUC-SP & Educação & Educação \\
\hline
\end{tabular}

O Quadro 01 revela equilíbrio na análise técnica referente à modalidade, pois são 10 teses e 11 dissertações. Há, ainda, equilíbrio na distribuição temporal, com média e mediana de três produtos por ano, sendo que o ano em que houve mais defesas, cinco em 2013, foi seguido pelo ano de menor quantidade de defesas, 2014, reestabelecendo a média nos anos subsequentes. Com relação à área de concentração, pode-se considerar a existência de seis exceções, sendo uma dissertação da área de teologia, duas da área interdisciplinar e três da área de ensino. A maioria, 15 produtos, foram desenvolvidos, apresentados e defendidos em programas de Educação, área onde há grande interesse pela formação de professores, em amplo sentido.

Com relação às instituições de produção dos estudos, os dados revelam algo já esperado, ou seja, a maioria dos estudos gerados em universidade públicas, sendo 13 em universidades federais e duas em universidade estadual. Na sequência, foram localizados quatro estudos produzidos em universidades confessionais e dois em instituições de ensino superior da iniciativa privada. Contudo, a distribuição geográfica dos produtos revela dados díspares, sendo que nove defesas foram realizadas na região sul do país, nove na região sudeste, duas na região nordeste, uma na região centro-oeste e nenhuma na região norte. Isso chama a atenção e merece um olhar mais analítico em pesquisas futuras, pois, apesar da predominância das universidades nas regiões sul e sudeste,a população indígena brasileira concentra-se majoritariamente no norte. (IBGE, 2012). 
Na sequência do levantamento, ao tentar esquadrinhar os métodos de pesquisa mais utilizados, notamos que todas as teses e dissertações pautaram-se no que Richardson (2012) nomeou de natureza qualitativa de pesquisa. No entanto, se a pesquisa qualitativa foi unânime, os instrumentos preferidos, por sua vez, variaram substancialmente, incluindo o uso de diário de campo, o registro de história oral, a pesquisa participante, a revisão de literatura, a pesquisa documental, o grupo focal, a pesquisa etnográfica e até a etnomatemática. No levantamento, foram identificados 31 instrumentos distintos, a partir da denominação dada pelos próprios autores, sendo que a entrevista foi o aporte metodológico mais foi utilizado, aparecendo em oito dos 21 das pesquisas inventariadas. Esse dado é importante, pois a entrevista é excelente método de dar voz aos sujeitos do estudo.

Ainda metodologicamente relevante, notamos que alguns pesquisadores deixaram expresso qual etnia indígena era foco de sua pesquisa, sendo que alguns casos foram estudados duas ou mais etnias distintas. Contudo, mesmo que algumas pesquisas não trabalharam com etnias específicas (ou não expressaram no texto), foi tomado o cuidado de mencionar ou descrever o local de morada dos sujeitos da investigação. Assim, das pouco mais de trezentas etnias indígenas já mapeadas no território brasileiro (IBGE, 2012), apenas 13 foram investigadas pela pós-graduação nestes últimos anos, sendo: Kaingang, Ticuna, Krikati, Maxakali, Puyanawa, Mayrobi, Apiaká, Kayabi, Tupinikim, Guarini, Tremembé,Pataxó e Cinta-Larga. Eis mais uma contundente lacuna a ser preenchida em estudos futuros.

Seguindo o roteiro proposto para o levantamento, verificamos que os objetivos das teses e dissertações eram bem específicos, dificultando sua catalogação. Mesmo assim, foi possível identificar uma distribuição um pouco irregular entre as investigações de cunho bibliográfico e documental e as de imersão específica em escolas indígenas. Uma quantidade significativa dos estudos focou na análise de políticas públicas estaduais, e outra boa parte buscou analisar estruturas curriculares, projetos pedagógicos e outros documentos da formação de professores indígenas no ensino superior. Dos estudos em campo, pode-se dizer que a maioria se preocupou com a questão da linguagem, analisando a educação bilíngue. A análise dos objetivos, portanto, indica a necessidade de novas investigações nos lugares onde efetivamente acontece a educação indígena.

Ao final do levantamento, pode-se dizer que, de modo geral, os trabalhos mapeados indicam que tem havido significativo aumento na formação inicial e continuada do professor preocupada com o contexto no qual os povos estão situados, além da valorização da cultura e biliguismo. Nas sessões seguintes do artigo, nos debruçamos novamente sobre as teses e dissertações, com o propósito de identificar e analisar com mais propriedade como tem sido tratadas as formações inicial e continuada do professorado para a educação escolar indígena. Começamos, então, pela formação inicial.

\section{A FORMAÇ̃̃O INICIAL DOS PROFESSORES DA EDUCAÇÃO ESCOLAR INDIGENA}

As teses e dissertações analisadas indicam que, para a formação inicial dos professores indígenas, é fundamental qualificar o debate sobre a prática da interculturalidade no contexto da educação escolar indígena. Isso quer dizer que é preciso identificar e reconhecer, nos espaços educativos, que os elementos socioculturais dos povos devem ser respeitados, compreendidos e ensinados a crianças e adultos, como forma de preservação da identidade (BURATTO, 2010; LEME, 2010; BENDAZZOLI, 2011; BRITO, 2012; SILVA, 2012; NASCIMENTO FILHO, 2013; RIBEIRO, 2013; ALVES, 2015; SANTOS 2015; VALENTINI, 2016).

Orellana (2011), por exemplo, menciona que a educação do campo brasileira, na especificidade da educação escolar indígena, tem suas primeiras experiências de formação dos professores nas iniciativas desenvolvidas pelas Organizações não Governamentais (ONG), oriundas da igreja católicas e cristãs evangélicas. Tal processo “[...] inicia-se a partir do final da década de 1970 e início de 1980, após as intensificações dos contatos dos povos indígenas com a sociedade, percebendo-se a importância da escolarização formal dos alunos, mas que esta deveria ser conduzida pelos próprios 
indígenas.” (p. 42). A autora, ainda, menciona a falta de formação inicial adequada, dificultando o trabalho sob o viés da interculturalidade no processo de formação desses professores indígenas. Para Orellana (2011), no contexto de sua pesquisa, não foram considerados os diferentes sujeitos envolvidos no processo de formação, tampouco as relações entre os conhecimentos indígenas e os do currículo regular, no processo educacional.

Na mesma direção, Silva (2012) explica que a educação para aceitação e compreensão da diversidade cultural deve acontecer da necessidade de envolvimento na vida social do próprio índio, de forma que possa interferir no contexto local, municipal, estadual e nacional, em defesa dos interesses dos índios como cidadão brasileiro.

Por isso, é preciso considerar, conforme Silva (2015, p. 13), que “[...] historicamente, a introdução da escola no meio indígena serviu de instrumento de imposição de valores alheios e de negação de identidades diferenciadas.” O autor menciona processos de escolarização antigos, como a catequização que teve início com a chegada dos portugueses em território nacional, no século XVI, e mais recentes, como o estabelecimento de uma educação escolar que promoveria uma "comunhão nacional”. Outras teses analisadas, de certa forma, também apontam que, para a valorização da biliguismo e interculturalidade, deverá existir uma necessidade de apoderamento das políticas públicas educacionais voltadas para a educação escolar indígena. Tal apoderamentotem a atuação do professor indígena como principal articulador entre comunidade local, organizações não governamentais e secretarias de educação. (BURATTO, 2010; BENDAZZOLI, 2011).

Além do respeito aobiliguismo e à interculturalidade, Nascimento filho (2013) identifica nos relatos os professores formadores, as principais dificuldades que interferem no ensino e aprendizagem. Segundo o autor, constituem os maiores entraves a não aceitação imediata da implantação de um curso superior nas comunidades indígenas, a não compreensão da Língua Portuguesa e o vocabulário dos textos distante da realidade indígena. Ademais, menciona que o papel do professor é ressignificar a forma de abordar os conteúdos na construção do conhecimento, facilitando a aprendizagem, tornandoos pesquisadores de sua própria cultura.

Nesse sentido, cabe lembrar que os povos indígenas também são brasileiros, portanto, detentores dos mesmos direitos de todo e qualquer cidadão. Por isso, devem também receber uma educação na qual se empoderem dos conhecimentos historicamente construídos. A pesquisa de Gonçalves (2016), por exemplo, evidência a necessidade de desenvolver práticas das instituições públicas e privadas formadoras conforme às especificidades de coletivos de professores, os quais reivindicam uma formação diferenciada, que possibilite a participação coletiva e a transformação da realidade escolar de seus povos. Trata-se, obviamente, da indissociabilidade institucional do tripé universitário ensino-pesquisa-extensão, que deve estar a serviço da formação inicial de professores na e para a educação indígena.

Isso pode ser visto em Sousa (2013), que aponta significativo aumento na demanda pela formação de professores indígenas. Segundo o autor, essa profissionalização relaciona-se intrinsecamente à garantia da igualdade de condições para a sólida formação científica, técnica, cultural, ética e política de todos os profissionais da educação, no entanto, deverá existir sempre uma percepção diferenciada e a valorização das tradições milenares. Dessa forma, pode-se considerar que a escola do ensino básico e a universidade ganharam um novo sentido para o povo indígena, tornando-se um meio de acesso, valorização e sistematização de saberes clássicos e tecnológicos.

Assim, ao tratar da formação inicial de professores da educação escolar indígena, Sousa (2017) menciona a importância de haver mais discussões sobre o papel da universidade e seu compromisso político com a sociedade. Especificamente, a autora cita compromissos com a classe trabalhadora e com as populações indígenas brasileiras. Dessa forma, Sousa (2017) propõe que as universidades atuem na formação inicial específica para os professores indígenas, para que esses lecionem em suas próprias comunidades. 
Entende-se que as instituições formadoras precisam rever seus currículos, analisando as fragilidades que vêm sendo apontadas, sobretudo, no que diz respeito à separação da teoria e da prática educacionais para ensino indígena. Isso seria algo a ser superado, uma vez que a necessidade de uma integração destes dois pontos é fundamental para se alcançar uma escolarização de excelência.

Essas ideias apresentadas pelos autores vão ao encontro do que foi apresentado na Resolução CNE 1/2015 (BRASIL, 2015) que institui as Diretrizes Curriculares Nacionais para a Formação de Professores Indígenas em cursos de Educação Superior e de Ensino Médio. Dentre outros, a referida resolução apresenta avanços para a educação indígena, cobrindo pontos relevantes expressos pelos autores das teses e dissertações mapeadas neste artigo. Como exemplo claro, podemos citar os "princípios da formação de professores indígenas”, reiterando o compromisso do Estado, garantia de padrões de qualidades, respeito à diversidade, garantia de formação inicial e continuada etc.

O eixo fundamental do currículo de formação inicial de professores é, segundo Imbernón (2011), o desenvolvimento da capacidade de refletir sobre a própria prática docente, com o objetivo de aprender a interpretar, compreender e refletir sobre a realidade social e à docência. Contudo, o professor não deve refletir unicamente sobre sua prática, indo além dos muros da instituição onde atua, para compreender os interesses subjacentes à realidade social. É sobre esta prerrogativa que a formação inicial de professores indígenas e para a educação indígena deve se assentar.

\section{FORMAÇ̃̃O CONTINUADA DE PROFESSORES DA EDUCAÇÃO ESCOLAR}

A formação continuada de professores é caracterizada como todo e qualquer aperfeiçoamento profissional elencados em seus mais variados tipos, tais como: extensão universitária ou voluntária, cursos de capacitação, atualização, aperfeiçoamento e pós-graduação lato e/ou stricto sensu, participação em eventos como congressos e oficinas. A concepção de formação continuada reforça a perspectiva de caráter social, contrapondo-se à formação individualizada, voltada tão somente para a certificação. Isso porque propõe a compreensão da formação do sujeito social que, para além da sua formação específica, contribui para o seu entorno social.

Vimos, no levantamento realizado, que as pesquisas de Bernardi (2011), Antunes (2012), Ferreira (2013), Dias (2015) e Sousa (2013) evidenciam que, assim como na formação inicial, na formação continuada busca-se um diálogo entre os saberes indígenas e os da academia, na perspectiva da interculturalidade e do biliguismo. Tais pesquisas indicam haver um esforço para uma educação escolar indígena construtora de um currículo articulado à vida, à interculturalidade, à sobrevivência da memória, da cultura e da língua materna. Já em Alves (2015) e Silva (2015), verifica-se que uma quantidade relevante das formações continuadas oficiais são oferecidas, via parcerias com universidades federais, na modalidade de Educação a Distância (EaD). Como presença da tecnologia na educação, já não é mais novidade que o incentivo a essa prática de formação continuada pode, inclusive, permitir a criação de redes específicas de capacitação de professores indígenas e para a educação indígena.

Segundo Grupioni (2003), os processos de formação continuada almejam possibilitar que os professores indígenas desenvolvam um conjunto de competências profissionais que lhes permita atuar, de forma responsável e crítica, nos contextos interculturais e sociolinguísticos nos quais as escolas indígenas estão inseridas. Em muitas situações, cabe ao professor indígena atuar como mediador e interlocutor de sua comunidade com os representantes do mundo de fora da aldeia e com a sistematização e organização de novos saberes e práticas. Os estudos de Bendazzoli (2011), Maders (2013), Soares (2011) e Marcelino (2014) mencionam a contribuição do trabalho colaborativo para a formação continuada do professor indígena, o qual dever ser um espaço de diálogo e de transformação local. 
De certa maneira, a resolução CNE 1/2015 (BRASIL, 2015) busca atender ao que foi identificado nas teses e dissertações. Isso porque o documento expressa que a formação de professores deve compreender o trabalho docente como uma ação educativa agregada ao processo pedagógico intencional, voltado à valoração cultural, ética, estética e política "em diálogo constante entre diferentes visões de mundo.” (BRASIL, 2015, p. 03). A resolução expressa o direito à formação continuada do professor indígena e para a educação indígena, a partir de uma ampla compreensão contextualizada dos povos indígenas, a fim de assegurar a produção e difusão dos conhecimentos essências para a escolarização dos alunos pertencentes a esses povos.

\section{CONSIDERAÇÕES FINAIS}

No final do século passado Monte (2000) escrevia sobre a formação de professores para a educação escolar indígena, e as iniciativas de movimentos sociais e outras formas de organização não institucionalizadas como formas de educar a população indígena brasileira. Tais iniciativas buscavam suprir um déficit secular de oferta de educação, o qual passava a ser alvo de discussões mais amplas a respeito da criação de políticas públicas e da formalização de resoluções específicas, incluindo a presença da universidade na formulação de diretrizes para a educação escolar indígena e a formação específica para seu magistério. Neste século, políticas públicas e documentos legais já são uma realidade. Isso não significa, obviamente, que a dívida histórica foi sanada, mas apresenta indícios positivos. Ao invés de batalhar por sua existência, agora é momento de discutir sua manutenção, ampliação e qualidade dos programas de formação.

As produções mapeadas remetem a uma necessidade de valorizar e compreender a cultura indígena historicamente construída. Pode-se considerar que, de forma geral, todos os seus autores indicam a necessidade de se investir na formação inicial e continuada de professores com um olhar atento à biliguismo e interculturalidade. Ainda, nas 10 teses e 11 dissertações constatamos que a formação inicial e continuada de professores indígenas remetem à importância de uma reflexão crítica, a fim de buscar estratégias para promover a interação dos variados tipos de conhecimentos que se desenvolvem e se entrelaçam no processo de escolarização: de um lado, os conhecimentos ditos universais, aqueles que todo estudante, indígena ou não, deve ter acesso, e, do outro, os conhecimentos étnicos, próprio do contexto social no qual estão alocados.

No mapeamento, algumas lacunas foram identificadas. Primeiro, em relação à distribuição geográfica na qual as pesquisas realizadas sobre o tema formação de professores indígenas, encontramos um déficit de produções principalmente originadas em instituições nas regiões norte e nordeste. Sobre um olhar mais analítico em pesquisas futuras, evidencia-se que população indígena brasileira concentra-se majoritariamente no norte, e em menor proporção nas regiões sudeste e sul, existindo uma necessidade latente de novos estudos nestas regiões desprovidas de estudos na temática pesquisada, exatamente onde a maioria da população indígena brasileira se concentra. Apesar da concentração das universidades brasileira nas regiões sul e sudeste, essa não deve ser uma justificativa para que a maioria das pesquisas continue a serem desenvolvidas longe dos lugares em que há maior incidência de população indígena, portanto comunidades que deveriam se beneficiar dos resultados das pesquisas acadêmicas.

Na sequência, constatou-se, que alguns pesquisadores expressaram qual (ou quais) etnia indígena estava em evidência no estudo. Mesmo assim, apenas 13 etnias distintas apareceram nas teses e dissertações mapeadas. Isso equivale a quase três centenas de etnias ainda por serem estudadas na questão de sua formação específica de professores.

Por fim, a última lacuna identificada no mapeamento sistemático diz respeito especificamente à metodologia empregada. Apesar dos materiais e métodos terem sido utilizados corretamente e de forma coerente com seus objetivos, ficou patente a necessidade de mais estudos empíricos, nos lugares onde o professor indígena ou formado para educação indígena irá efetivamente atuar. Notou-se, ainda, 
que os estudos que trataram de conteúdos específicos da formação estavam voltados para linguagem ou matemática, deixando de fora, portanto, conteúdos de história, geografia, artes, ciências etc.

Ademais, as políticas públicas educacionais dentre elas as políticas de formação de professores e as políticas da educação escolar indígena foram citadas em todas as dissertações e teses catalogados neste trabalho, isso revela a importância das políticas públicas para o embasamento teórico das pesquisas analisadas. Compreendeu-se, assim, a necessidade de se conhecer a legislação no cenário das políticas públicas educacionais, que tem trazido à tona muitas discussões acerca da sua formação profissional e consequentemente a prática pedagógica de professores indígenas.

Ao final, podemos considerar que as lacunas encontradas no mapeamento dizem respeito a um melhor aprofundamento dos estudos sobre formação de professores na e para a educação indígena. Isso quer dizer que as teses e dissertações mapeadas demonstram avanço na área e que as diretrizes e políticas públicas têm surtido efeitos positivos. Obviamente, estamos longe do ideal, mas, o fato de novos encaminhamentos legais terem surgido recentemente, como o caso da resolução CNE 1/2015 (BRASIL, 2015), evidenciam preocupação mais ampla com a questão da educação para todos. Esperamos, portanto, que o levantamento aqui realizado, as lacunas identificadas e os progressos reconhecidos se transformem em novas e mais densas pesquisas.

\section{REFEREENCIAS}

ALVES, L. M. As tecnologias de informação e comunicação em licenciatura intercultural indígena: caso da UFC. 2015. 141 f. Tese (Doutorado em Educação) - Programa de Pós-graduação em Educação, Pontifícia Universidade Católica de Goiás, Goiânia, 2015.

ANTUNES. C. P. Experiências de formação de professores Kaingang no Rio Grande do Sul. 2015. 122 f. Dissertação (Mestrado em Educação) - Faculdade de Educação, Universidade Federal do Rio Grande do Sul, Porto Alegre, 2012.

BENDAZZOLI, S. Políticas públicas de educação escolar indígena e a formação de professores ticunas no Alto Solimões/AM. 2011. 437 f. Tese (Doutorado em Educação) - Faculdade de Educação, Universidade de São Paulo, São Paulo, 2011.

BERNARDI, L. T. M. S. Formação continuada em matemática do professor indígena Kaingang: enfrentamentos na busca de um projeto educativo. 2011. 267 f. Tese (Doutorado em Educação Científica e Tecnológica) - Programa de Pós-Graduação em Educação Científica e Tecnológica, Universidade Federal de Santa Catarina, Florianópolis, 2011.

BURATTO, L. G. Prevenção de deficiência: programa de formação para professores kaingang na terra indígena Ivaí-Paraná. 2010. 202 f. Tese (Doutorado em Educação Especial) - Centro de Educação e Ciências Humanas, Universidade Federal de São Carlos, São Carlos, 2010.

BRITO, R. P. S. Apropriação de práticas de numeramento em contexto de formação de educadores indígenas. 2012. 268 f. Dissertação (Mestrado em Educação) - Faculdade de Educação, Universidade Federal de Minas Gerais, Belo Horizonte, 2012.

BRASIL. Conselho Nacional da Educação. Resolução no 1, de 7 de janeiro de 2015. Institui Diretrizes Curriculares Nacionais para a Formação de Professores Indígenas em cursos de Educação Superior e de Ensino Médio e dá outras providências. Diário Oficial da União, Brasília, 08 jan. 2015. Disponível em: http://www.in.gov.br/materia/-/asset_publisher/Kujrw0TZC2Mb/content/id/32100518/do1-201501-08-resolucao-n-1-de-7-de-janeiro-de-2015-32100495. Acesso em: 15 maio 2018.

BRASIL. Ministério da Educação. Conselho Nacional de Educação. Câmara de Educação Básica (CEB). Parecer $\mathrm{n}^{0}$ 13, de 10 de maio de 2012. Dispõe sobre as Diretrizes Nacionais para o funcionamento das escolas indígenas. Diário Oficial da União, Brasília, 15 jun. 2012. Disponível em: 
http://portal.mec.gov.br/index.php?option=com_docman\&view=download\&alias=10806-pceb013-12pdf\&Itemid=30192. Acesso em: 15 maio 2018.

BRASIL. Decreto $\mathbf{n}^{0}$ 6.861, de 27 de maio de 2009. Dispõe sobre a Educação Escolar Indígena, define sua organização em territórios etnoeducacionais, e dá outras providências. Diário Oficial da União, Brasília, 28 maio 2019. Disponível em: http://www.planalto.gov.br/ccivil_03/_Ato20072010/2009/Decreto/D6861.htm. Acesso em: 15 maio 2018.

BRASIL. Ministério da Educação. Lei de Diretrizes e Bases da Educação Nacional - LDB nº 9.394, de 20 de dezembro de 1996. Brasília: MEC, 1996.

BRASIL. Constituição da República Federativa do Brasil. Brasília: Imprensa Oficial, 1988.

DIAS, A. L. L. Formação específica dos professores indígenas Krikati e prática pedagógica bilíngue. 2015. 114 f. Dissertação (Mestrado em Ensino) - Programa de Pós-graduação em Ensino, Centro Universitário UNIVATES, Lajeado, 2015

FERREIRA, W. A. A. Educação escolar indígena na terra indígena Apiaká-Kayabi em Juara MT: resistências e desafios. 2013. 181 f. Tese (Doutorado em Educação) - Faculdade de Educação, Universidade Federal do Rio Grande do Sul, Porto Alegre, 2013.

GONÇALVES, G. J. Formação de professores indígenas e quilombolas: desafios e perspectivas. 2016. 119 f. Dissertação (Mestrado em Interdisciplinalidade em Estudos Latino-Americanos) Programa de Pós-Graduação Interdisciplinar em Estudos Latino-Americanos, Universidade Federal da Integração Latino-Americana, Foz do Iguaçu, 2016.

GRUPIONI, L. D. B. Experiências e Desafios na Formação de Professores Indígenas no Brasil. Em Aberto, Brasília, v. 20, n. 76, p. 13-18, fev. 2003.

IBGE. Censo demográfico 2010: características gerais dos indígenas - resultados do universo. Rio de Janeiro: IBGE, 2012. 244 p.

IMBERNÓN. F. Formação docente e profissional: formar-se para a mudança e a incerteza. São Paulo: Cortez, 2011.

LEME, H. A. S. Formação superior de professores indígenas de matemática em Mato Grosso do Sul: acesso, permanência e desistência. 2010. 185 f. Tese (Doutorado em Educação) - Faculdade de Educação, Universidade de São Paulo, São Paulo, 2010.

MADERS, S. Educação escolar indígena, intercultura e formação de professores (as): uma pesquisa a partir das proposições da biologia do amor e da biologia do conhecimento de Humberto Maturana. 2013. 160 f. Dissertação (Mestrado em Educação) - Programa de Pós-graduação em Educação, Universidade Federal de Santa Maria, Santa Maria, 2013.

MARCELINO, O. T. Educação escolar Tupinikim e Guarani: experiências de interculturalidade em aldeias de Aracruz, no Estado do Espírito Santo. 2014. 241 f. Tese (Doutorado em Educação) - Centro de Educação - CE, Universidade Federal do Espírito Santo, Vitória, 2014.

MONTE, N. L. Os outros, quem somos? Formação de professores indígenas e identidades culturais. Cadernos de Pesquisa, São Paulo, n. 111, p. 7-29, dez. 2000.

NASCIMENTO FILHO, V. B. O papel do professor na formação docente indígena: uma reflexão a partir das impressões dos professores formadores que atuaram no curso de licenciatura para professores indígenas do Alto Solimões. 2013. 79 f. Dissertação (Mestrado em Teologia) - Programa de Pós-graduação em Teologia, Escola Superior de Teologia Faculdades - EST, São Leopoldo do Sul, 2013. 
ORELLANA, A. D. A. Y. Formação de professores indígenas em Rondônia: interculturalidade e seus desafios. 2011. 98 f. Dissertação (Mestrado em Educação) - Faculdade de Educação, Pontifícia Universidade Católica de São Paulo, São Paulo, 2011.

PEREIRA, P. S.; FORTUNATO, I.; LOURENÇO, C. A educação ambiental em periódicos brasileiros de ensino de física. Revista Brasileira de Educação Ambiental, São Paulo, v. 11, n. 2, p. 127-138, jun. 2016.

RIBEIRO, S. H. M. Políticas Afirmativas na universidade federal do Ceará: desafios e conquistas da educação diferenciada no curso de Magistério Indígena Tremembé Superior- MITS. 2013. 92 f. Dissertação (Mestrado em Políticas Públicas e Gestão da Educação Superior) - Programa de Pósgraduação em Políticas Públicas e Gestão da Educação Superior (Poleduc), Universidade Federal do Ceará, Fortaleza, 2013.

RICHARDSON, R. J. Pesquisa social: métodos e técnicas. São Paulo: Atlas, 2012.

SANTOS, J. D. Saberes etnomatemáticos na formação de professores indígenas do curso de licenciatura intercultural na Amazônia. 2015. 121 f. Dissertação (Mestrado Programa de PósGraduação em Educação em Ciências e Matemática) - Faculdade de Física, Pontifícia Universidade Católica do Rio Grande do Sul, Porto Alegre, 2015.

SILVA, I. M. O. Os cursos de magistério indígena do estado do Maranhão e as implicações na formação dos professores Krikati numa perspectiva específica e diferenciada. 2012. $138 \mathrm{f}$. Dissertação (Mestrado em Educação) - Programa de Pós-graduação em Educação, Universidade Federal do Maranhão, São Luís, 2012.

SILVA, J. A. C. Políticas públicas de educação escolar indígena e a formação de professores indígenas no Acre. 2015. 181 f. Tese (Doutorado em Educação) - Programa de Pós-graduação em Educação, Universidade Federal do Paraná, Curitiba, 2015.

SILVA, R. H. D. Escolas em movimento: trajetórias de uma política indígena de educação. Cadernos de Pesquisa, São Paulo, n. 111, p. 31-45, dez. 2000.

SOUSA, J. D. Professores indígenas Maxakali e a prática em suas aldeias: mudanças e entraves. Dissertação de mestrado. 2013. 117 f. Dissertação (Mestrado em Gestão e Avaliação em Educação Pública) - Faculdade de Educação, Universidade Federal de Juiz de Fora, Juiz de Fora, 2013.

SOUSA, F. B. Sentido ideias, germinando saberes: movimentos de apropriação (afetiva) da política de territórios etnoeducacionais por professores Kaingang e Guarani no RS. 2017. 222 f. Tese (Doutorado em Educação) - Faculdade de Educação, Universidade Federal do Rio Grande do Sul, Porto Alegre, 2017.

SOARES, M. D. O. Os processos de construção de uma escola diferenciada: o caso da escola indígena Ixbãy Rabu Puyanawa. 2011. 213 f. Tese (Doutorado em Educação) - Programa de PósGraduação em Educação, Universidade Federal de Minas Gerais, Belo Horizonte, 2011.

VALENTINI, A. A. História e cultura indígena nas licenciaturas em História: USP, UNESP/FCLAssis, UNICAMP e PUC-SP. 2016. 279 f. Tese (Doutorado em Educação: História, Política, Sociedade) - Faculdade de Educação, Pontifícia Universidade Católica de São Paulo, São Paulo, 2016. 